\title{
Optimal Extraction of Photovoltaic Model Parameters Using Gravitational Search Algorithm Approach
}

\author{
C. Saravanan1, K. Srinivasan² \\ ${ }^{1}$ North East Frontier Technical University, Arunachal Pradesh, India \\ ${ }^{2}$ Department of EEE, Tagore Engineering College, Chennai, India \\ Email:kamsaravan@gmail.com,omsrivas@yahoo.co.in
}

How to cite this paper: Saravanan, C. and Srinivasan, K. (2016) Optimal Extraction of Photovoltaic Model Parameters Using Gravitational Search Algorithm Approach. Circuits and Systems, 7, 3849-3861. http://dx.doi.org/10.4236/cs.2016.711321

Received: March 19, 2016

Accepted: April 20, 2016

Published: September 22, 2016

Copyright $\odot 2016$ by authors and Scientific Research Publishing Inc. This work is licensed under the Creative Commons Attribution International License (CC BY 4.0).

http://creativecommons.org/licenses/by/4.0/

\begin{abstract}
Extraction of accurate Photo Voltaic (PV) model parameters is a challenging task for PV simulator developers. To mitigate this challenging task a novel approach using Gravitational Search Algorithm (GSA) for accurate extraction of PV model parameters is proposed in this paper. GSA is a population based heuristic optimization method which depends on the law of gravity and mass interactions. In this optimization method, the searcher agents are collection of masses which interact with each other using laws of gravity and motion of Newton. The developed PV model utilizes mathematical equations and is described through an equivalent circuit model comprising of a current source, a diode, a series resistor and a shunt resistor including the effect of changes in solar irradiation and ambient temperature. The optimal values of photo-current, diode ideality factor, series resistance and shunt resistance of the developed PV model are obtained by using GSA. The simulations of the characteristic curves of PV modules (SM55, ST36 and ST40) are carried out using MATLAB/ Simulink environment. Results obtained using GSA are compared with Differential Evolution (DE), which shows that GSA based parameters are better optimal when compared to DE.
\end{abstract}

\section{Keywords}

GSA, Photo Voltaic, Parameter Extraction, MATLAB/Simulink

\section{Introduction}

World's primary energy consumption is increasing by about $2.5 \%$ in every year. Though most of the energy demand is shared by conventional energy sources, the en- 
vironmental impact on usage of these sources has been disintegrative with the issues such as pollution, global warming, and excessive greenhouse effect. To overcome the above mentioned effects, finding sustainable alternatives is becoming increasingly urgent. To meet considerable percentage of demand, renewable energy sources are installed to share $3.9 \%$ of global power generation. The rapid growth of renewable power generation continues and this opens a new era for solar power generation. Solar energy is obviously environmentally advantageous relative to any other energy source. The increase in demand for solar industry over the past several years has expanded the importance of PV system design and application for more reliable and efficient operation.

PV module represents the fundamental power conversion unit of a PV generator system. PV module is a series connection of PV cells where each cell exhibits non-linear characteristics. To use PV module in the simulation environment, it is necessary that the model should produce the PV cell non-linear characteristics. For efficient design of the PV array in simulation environment, it is essential to use the accurate magnitudes of the panel parameters. But, these parameters are usually unknown to the user and hence the parameters are needed to be extracted by a proper extraction method before designing the PV array. Nowadays, a single diode PV model with a photo current source $I$, a single diode $D$, a series resistance $R_{s e}$ and a shunt resistance $R_{s h}$ is used as the equivalent circuit of a PV cell [1] [2]. Hence, the parameters needed to be extracted are photo current, diode ideality factor, series resistance and shunt resistance. For parameter extraction process, the values of $\mathrm{PV}$ array open circuit voltage $V_{o c}$ short circuit current $I_{s \mathcal{O}}$ voltage at maximum power point $V_{m p p}$, current at maximum power point $I_{m p p}$, temperature coefficient of open circuit voltage $K_{v}$ temperature coefficient of short circuit current $K_{i}$ and the maximum peak output power $P_{m p}$ are necessary. Generally, all these values for a PV array are available in manufacturers' data-sheet. Hence, most of the parameter extraction methods are based on manufacturers' data-sheet. In single diode PV model, the unknown currents are obtained by nodal analysis. The other parameters $R_{s e}$ and $R_{s h}$ are calculated from PV cell characteristics [3]. However, finding $R_{s e}$ and $R_{s h}$ from characteristics curve may not be more accurate. In addition to that, the value of these resistances depends on solar irradiation and ambient temperature. To resolve these issues, optimization techniques are introduced to optimize accurately the value of photo-current, diode ideality factor, series resistance and shunt resistance.

Genetic algorithm based optimization of the circuit parameters is slow and takes larger computation time [4]-[8]. In Particle Swamping Optimization, to extract the optimal value for $R_{s e}$ and $R_{s h}$, large number of iterations are to be evaluated, though the results are close to possible values [9]-[11]. Gravitational Search Algorithm (GSA) is a newly developed heuristic optimization method based on the law of gravity and mass interactions [12]. GSA has been confirmed to give higher performance in solving various nonlinear functions, compared with some well-known search methods. In [13], GSA was introduced to apply in parameter identification of hydraulic turbine governing system. Subsequent to the development of GSA, researchers tried to implement this algorithm to different applications. In this study GSA is implemented to optimize single 
diode PV model parameters. This paper is organized as follows: Section 2 provides an introduction to GSA. Section 3 provides a brief review of GSA for PV model parameters extraction, and the proposed objective function. Section 3.2 describes the procedure of GSA to the PV parameters optimization problem in a detailed manner. The results obtained are elaborated in Section 4.

\section{Gravitational Search (GS) Algorithm}

Over the last two decades, many researches has to be done for various types of algorithms like Evolutionary Approach (EA), Differential Evolution (DE), Particle Swarm Optimization (PSO) and etc. [9]-[11] to solve the optimal parameter extraction of PV modules. Rashedi et al., proposed one of the newest heuristic algorithm which is successfully applied to various benchmark problems [12]. GSA proved that it gives better convergence than GA and PSO under various conditions. This algorithm is mainly based on the Newton's law of gravity, "The gravitational force between two particles is directly proportional to the product of their masses and inversely proportional to the square of the distance between them". This algorithm gives the better optimal results which are obtained by various applications in an effective manner [13] [14]. To find the optimal value of series and parallel resistances in photo voltaic array, this paper adapts the above mentioned heuristic algorithm.

In the proposed GS algorithm, agents are considered as objects and their performance is measured by their masses. All these objects attract each other by the gravitational force and this force causes a global movement of all objects towards each other with heavier masses. Hence, masses cooperate using a direct form of communication, through gravitational force. The heavy masses - which correspond to good solutionsmove more slowly than lighter ones and this guarantees the exploitation step of the algorithm.

As per GS algorithm, each mass (agent) has four specifications:

1) Position;

2) Inertial mass;

3) Active gravitational mass and;

4) Passive gravitational mass.

The position of the mass corresponds to a solution of the problem and its gravitational and inertial masses are determined using a fitness function. In other words, each mass presents a solution and the algorithm is navigated by properly adjusting the gravitational and inertial masses. By lapse of time, we expect that the masses may be attracted by the heaviest mass. This mass will present an optimal solution in the search space.

\section{GS Algorithm for PV Model Parameters Extraction}

\subsection{Modelling of PV Array}

The building block of PV array is the Solar cell, which is basically a PN semiconductor junction that directly coverts light energy into electricity. PV cells are grouped in larger 
units called PV modules which are further interconnected in a parallel-series configuration to form PV arrays or PV generators. Figure 1 shows the equivalent circuit of a PV cell. To extract the PV array parameters like $I_{p v} a, R_{s e}$ and $R_{s h}$ a PV mathematical model is used according to the following set of equations [1] [2].

The voltage-current characteristic equation of a solar cell is given as,

$$
I=I_{p v}-I_{o}\left[\exp \left(\frac{q\left(V+I R_{S e}\right)}{K T a}\right)-1\right]-\left[\frac{V+I R_{S e}}{R_{S h}}\right]
$$

where, $I_{p v}$ is a light-generated current or photocurrent, $I_{o}$ is the cell saturation of dark current, $q\left(=1.6 \times 10^{-19} \mathrm{C}\right)$ is an electron charge, $K\left(=1.38 \times 10^{-23} \mathrm{~J} / \mathrm{K}\right)$ is a Boltzmann's constant, $T$ is the cell's working temperature, " $a$ " is an ideal factor, $R_{s h}$ is a shunt resistance and $R_{s e}$ is a series resistance of solar cell. The photo-current $I_{p v}$ mainly depends on the solar insolation and cell's working temperature and is given by,

$$
I_{p v}=\left[I_{S C}+K_{i}\left(T-T_{n}\right)\right] H
$$

where, $I_{S C}$ is the cell's short-circuit current at $25^{\circ} \mathrm{C}$ and $1 \mathrm{~kW} / \mathrm{m}^{2}, K_{i}$ is the cell's shortcircuit current temperature coefficient, $T_{n}$ is the cell's reference temperature and $H$ is the solar insolation in $\mathrm{kW} / \mathrm{m}^{2}$. The cell's saturation current $I_{o}$ varies with the cell temperature is

$$
I_{o}=\left[\frac{I_{S C}+K_{i}\left(T-T_{n}\right)}{\exp \left[\left(V_{O C}+K_{V}\left(T-T_{n}\right)\right) / a N_{S} V_{t}\right]-1}\right]
$$

where, $V_{O C}$ is the cell's open circuit current at $25^{\circ} \mathrm{C}$ and $1 \mathrm{~kW} / \mathrm{m}^{2}, K_{V}$ is the cell's open circuit voltage temperature coefficient, $N_{S}$ is the number of cells connected in series per string and $V_{t}$ is the thermal voltage given by, $V_{t}=K T / q$. The terminal equation of $\mathrm{PV}$ array for the current is given as,

$$
\begin{gathered}
I=N_{p} I_{p v}-N_{p} I_{o}\left[\exp \left(\frac{q\left(V+I R_{S M}\right)}{N_{S} K T a}\right)-1\right] \\
R_{S M}=N_{S} R_{S e} / N_{p}
\end{gathered}
$$

where, $N_{s}$ is number cells in series and $N_{p}$ is the number cells in parallel.

Hence the objective function using the Equations (1) to (4) is formulated as given below:

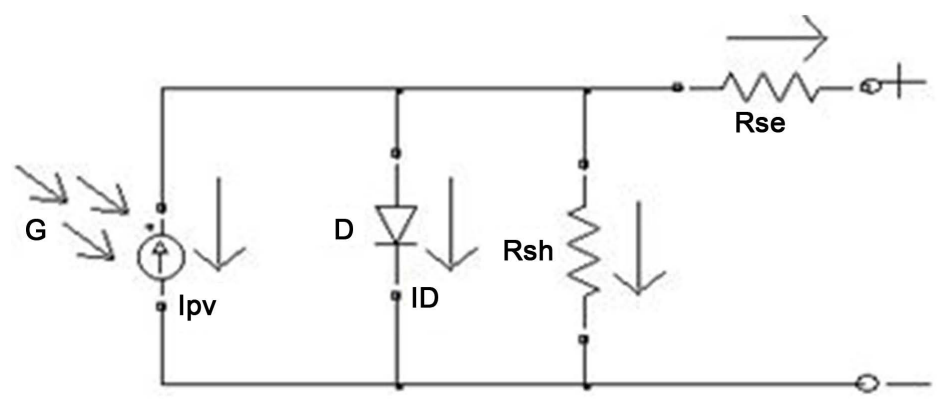

Figure 1. The equivalent circuit of a PV cell. 


$$
\text { Minimize } Y=\sqrt{\sum_{m=1}^{n} U\left(V_{m}, I_{m}, \varnothing\right)^{2}}
$$

where

$$
U(V, I, \phi)=I_{p v}-I_{o}\left(\mathrm{e}^{\frac{V+I R_{s e}}{a+V_{T}}}-1\right)-V \frac{I R_{s e}}{R_{s h}}-I .
$$

\subsection{GSA Implementation for Optimal Design of PV Model}

The detailed description of the algorithm to extract PV model parameters is presented below and the pictorial flowchart is shown in Figure 2.

(1)
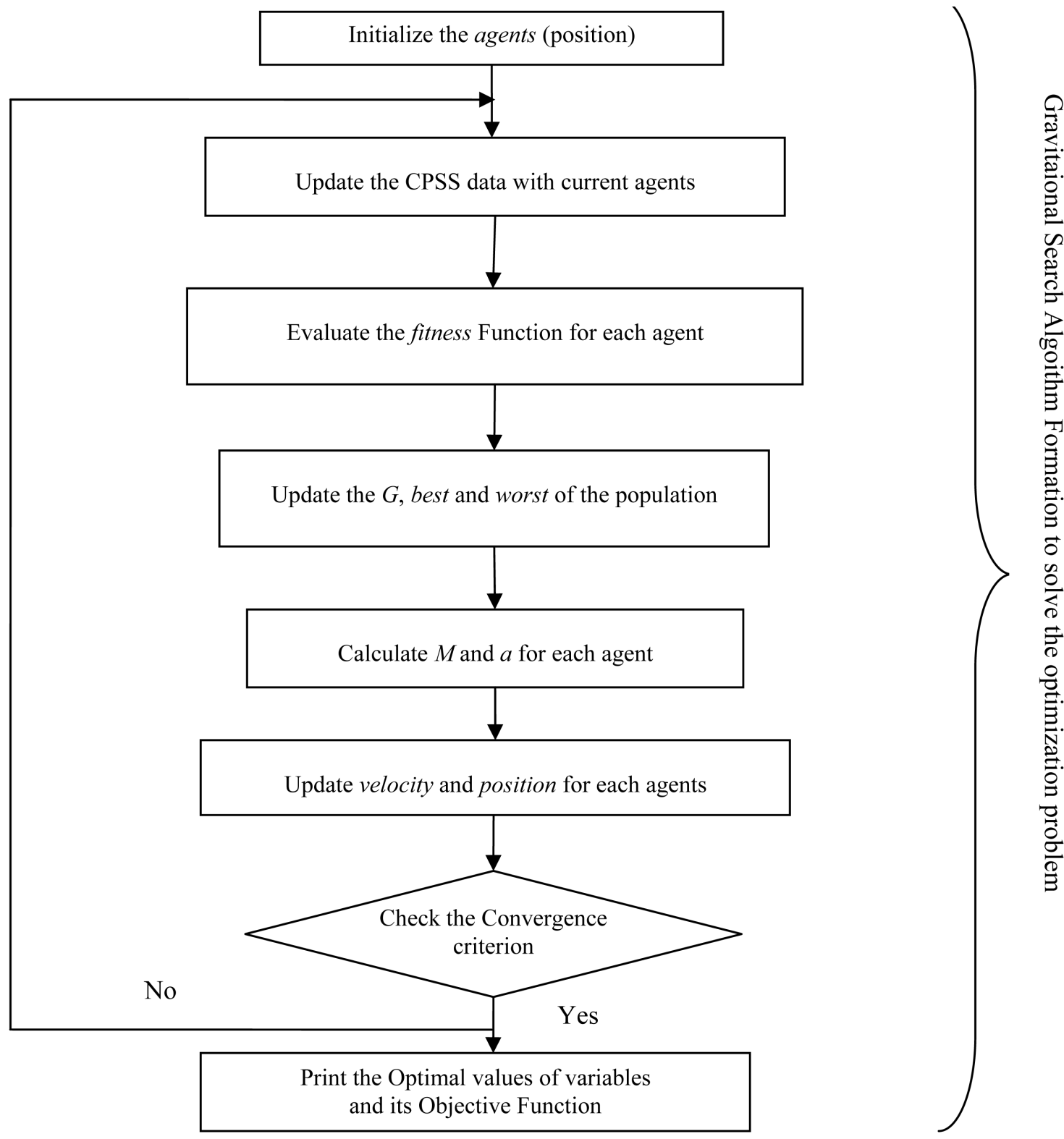

Figure 2. Pictorial flowchart. 


\subsubsection{Position}

A set of values for the I-V characteristics serves as the input data for the GSA. The parameters that are extracted by optimization are $I_{p r}, R_{s e}, R_{s h}$ and a are evaluated as $X_{k}$ in GSA.

Considering a system with $\mathrm{N}$ agents (masses), Position of the $K^{\text {th }}$ agent is defined by,

$$
X_{k}=\left[x_{k}^{1}, x_{k}^{2}, \cdots, x_{k}^{d}, \cdots, x_{k}^{N}\right] \text {, for } k=1,2,3, \cdots, N
$$

where $x_{k}^{d}$-Position of the $K^{\text {th }}$ agent in $d^{\text {th }}$ dimension.

\subsubsection{Fitness Evaluation}

The fitness value of each agent $x_{k}$ is evaluated using Equation (6). The best and worst value of each generation with respect to time were calculated using,

$$
\begin{aligned}
\operatorname{best}(t) & =\min _{l \in\{1, \cdots, N\}} Y(t) \\
\operatorname{worst}(t) & =\max _{l \in\{1, \cdots, N\}} Y(t) .
\end{aligned}
$$

\subsubsection{Gravitational Constant}

Gravitational constant $(G)$ is initialized at the beginning and at the later stages and is calculated as a function of time $(t)$ (to reduce the time control strategy).

$$
G(t)=G\left(G_{0}, t\right) \text {. }
$$

\subsubsection{Force}

During a time " $l$ ", the force between the agents " $k$ " and " $P$ " with respect to mass is given as,

$$
F_{k l}^{d}=G(t)\left[\frac{M_{p k}(t) \times M_{a l}(t)}{R_{k l}(t)+\varepsilon}\right]\left(x_{l}^{d}(t)-x_{k}^{d}(t)\right),
$$

where, (all the values are with respect to specific time " $t$ ");

$M_{p k}(t)$-Passive gravitational mass of agent $k$,

$M_{a l}(t)$-Active gravitational mass of agent $l ;$

$\varepsilon$-Small constant;

$G(t)$-Gravitational constant;

$R_{k l}(t)$-Euclidian distance between two agents $k$ and $l$. It is given by,

$$
R_{k l}(t)=X_{k}(t), X_{l}(t)_{2} \text {. }
$$

\subsubsection{Total Force}

The total force acting on a particle $k$ at $d^{\text {th }}$ dimension is given by,

$$
F_{k}^{d}(t)=\sum_{l=1, l \neq k}^{N} \operatorname{rand}_{l} F_{k l}^{d}(t),
$$

where, rand $_{1}$-Random number between the intervals [0-1].

$K_{\text {best }}$ is a function of time, with the initial value $K_{0}$ at the beginning and decreasing with time in such a way, at the beginning, all agents apply the force, and as time passes, $K_{\text {best }}$ is decreased linearly and at the end there will be just one agent applying 
force to the others. Therefore, Equation (11) could be written as,

$$
F_{k}^{d}(t)=\sum_{l \in k_{\text {best }}, l \neq k}^{N}\left(\operatorname{rand}_{l} F_{k l}^{d}(t)\right),
$$

where, $K_{\text {best }}$-Set of first $k$ agents with the best fitness value and biggest mass.

\subsubsection{Gravitational and Inertial Mass}

Gravitational and Inertial masses are calculated by using the following equations (assuming gravitational mass is equal to inertial mass),

$$
\begin{gathered}
M_{a k}=M_{p k}=M_{k k}=M_{k}, \text { for } k=1,2,3, \cdots, N, \\
m_{k}(t)=\frac{f i t_{k}(t)-\operatorname{worst}(t)}{\operatorname{best}(t)-\operatorname{worst}(t)}, \\
M_{k}(t)=\left[\frac{m_{k}(t)}{\sum_{l=1}^{N} m_{j}(t)}\right],
\end{gathered}
$$

where, $Y_{k}(t)$-Fitness value of the $k^{\text {th }}$ agent at time $t$.

\subsubsection{Acceleration}

By the law of motion, the acceleration of the agent $k$ in $d^{\text {th }}$ direction at time $t$ is found out by using the following relation,

$$
a_{k}^{d}(t)=\left[\frac{F_{k}^{d}(t)}{M_{k k}^{d}(t)}\right],
$$

where, $M_{k k}^{d}(t)$-Inertial mass of the agent $i$.

\subsubsection{Updating of Velocity and Position}

Velocity can be updated by summing the current velocity and its acceleration. Similarly, the position of particles can be updated by adding its previous position and its velocity.

$$
\begin{gathered}
v_{k}^{d}(t+1)=\operatorname{rand}_{k} \times v_{k}^{d}(t)+a_{k}^{d}(t), \\
x_{k}^{d}(t+1)=x_{k}^{d}(t)+v_{k}^{d}(t+1),
\end{gathered}
$$

where, rand $_{k}-$ Random number between the intervals [0-1]. Random numbers are used to give a randomized characteristic to the search.

\subsubsection{Convergence Criterion}

To obtain the best solution for the global optima, this algorithm stops its searching for the best solution by maximum iterations given for the optimal PV design problem.

\section{Results and Discussion}

The PV modelling method accuracy is validated by measured parameters of selected PV modules. The experimental ( $\mathrm{I}$ and V) data is extracted from the manufacturer's datasheet [15]. Three PV modules (SM55, ST36 and ST40) of different technologies are utilized for verification; these include the mono-crystalline and thin-film types. The specifications of the modules are given in Table 1. For GSA method, the simulation is done 
Table 1. Specifications for the three modules used in the experiments.

\begin{tabular}{cccc}
\hline Parameter & Mono-crystalline SM55 & Thin film ST40 & Thin film ST36 \\
\hline$I_{s c}$ & 3.45 & 2.59 & 2.68 \\
$V_{o c}$ & 21.7 & 22.2 & 22.9 \\
$I_{m p}$ & 3.15 & 2.41 & 2.279 \\
$V_{m p}$ & 17.4 & 16.6 & 15.8 \\
$K_{V} \mathrm{~m} /{ }^{\circ} \mathrm{C}$ & -0.077 & -0.1 & -0.1 \\
$K_{i} \mathrm{~m} /{ }^{\circ} \mathrm{C}$ & $1.38 \times 10^{-3}$ & $0.26 \mathrm{~mA}$ & $0.32 \mathrm{~mA}$ \\
$N_{s}$ & 36 & 42 & 42 \\
\hline
\end{tabular}

using MATLAB R2010b with Intel Core i3 CPU @ $2.53 \mathrm{GHz}$ processor, 3 GB RAM under windows 7 environment. And the SM55, ST36 and ST40 PV modules are used for simulation study. The parameters settings in GSA are: Agents-100, Iterations-100 and Power of R-1. The results obtained using the proposed GSA method is compared with DE in a judicial way.

\section{Fitness Value and Optimized Parameter Values by GSA}

Simulation results are obtained by executing the proposed GSA method at $1000 \mathrm{~W} / \mathrm{m}^{2}$ and $25^{\circ} \mathrm{C}$ temperature for 25 times. The GSA method obtains the global optimal value of objective function as $5.847 \times 10^{-12}, 9.6421 \times 10^{-12}$ and $5.1656 \times 10^{-12}$ for SM55, ST36 and ST40 PV modules respectively. Also, for experimental validation, the data is significantly fewer compared to the DE and $R_{s}$-model [10] as shown in Table 2. Among the 25 runs, best values are taken as the model parameters. From these results, it is evident that GSA outperforms DE in optimizing the objective function, which shows the effectiveness of GSA method. GSA tends to find the global optimum faster than other algorithms and hence has a higher convergence rate [9] [10]. Even, GSA proves its fast computational ability by returning those results within 29 - 31 seconds. GSA could be the unique algorithm faster than all other optimization techniques in these kinds of applications [9] as shown in Table 3. The convergence performance of each module is shown in Figures 3(a)-(c) by selecting its best one out of 25 runs.

Figures 4(a)-(c) and Figures 5(a)-(c) show the I-V and P-V curves for SM55, ST36 and ST40 respectively, for different levels of irradiance and temperatures. It can be seen that the I-V and P-V curve obtained by proposed model strongly agrees to the experimental data for all types of modules. In particular, the proposed model is very accurate at all irradiance and temperature levels.

\section{Conclusion}

This paper presents a powerful GSA method for extracting solar cell parameters. Number of parameters extracted is limited to four i.e. $I_{p r} a, R_{s e}$ and $R_{s h}$. The GSA method has been successfully applied to the PV modules SM55, ST36 and ST40 under different temperatures and solar insolations. The results obtained using GSA are better when 




(a)

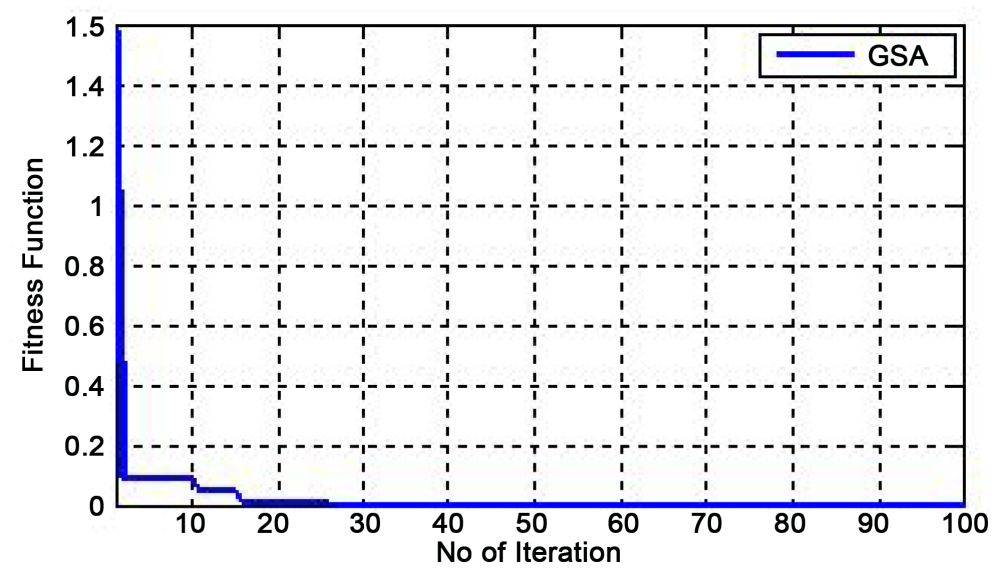

(b)

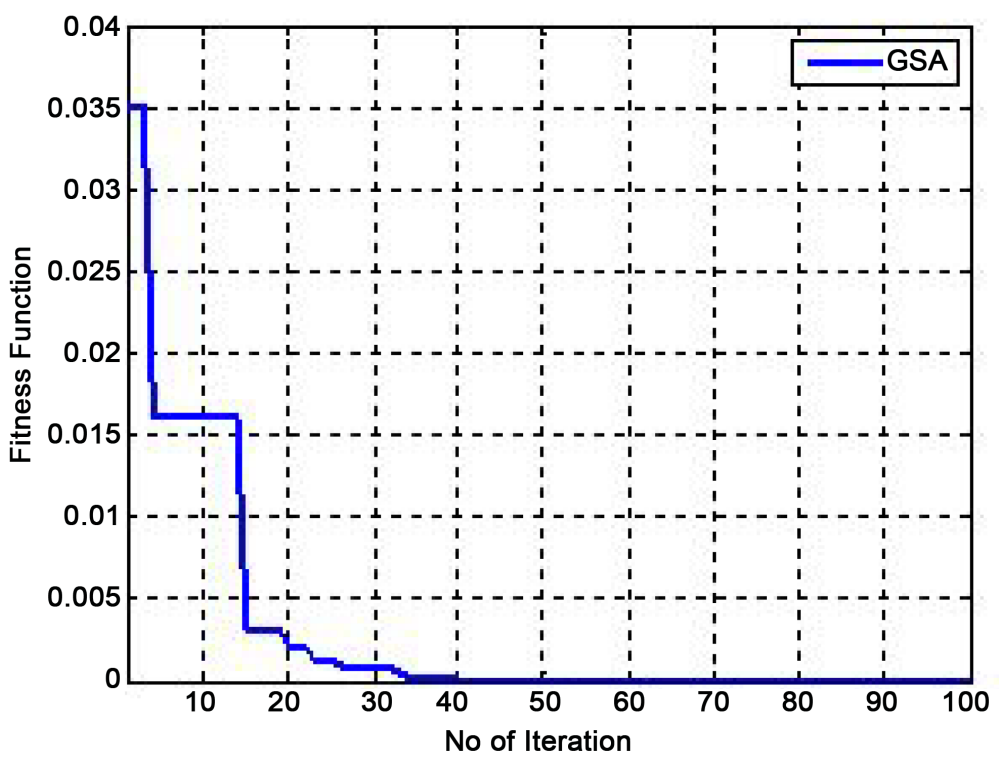

(c)

Figure 3. (a) Convergence performances of the fitness function with GSA for PV module ST40; (b) Convergence performances of the fitness function with GSA for PV module ST36; (c) Convergence performances of the fitness function with GSA for PV module SM55. 

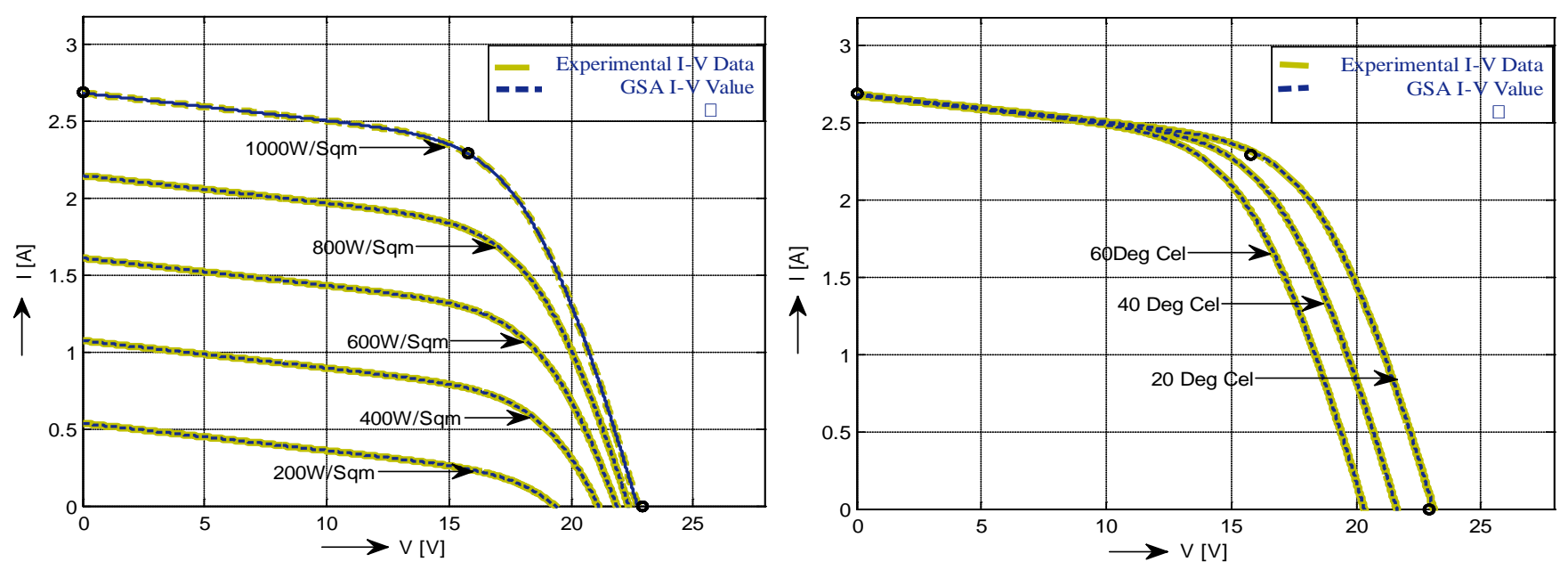

(a)


(b)


(c)

Figure 4. (a)-(c) I-V curves for different irradiation and temperature levels (a) ST36 (thin film); (b) SM55 (monocrystalline); and (c) ST40 (thin film). 



(a)
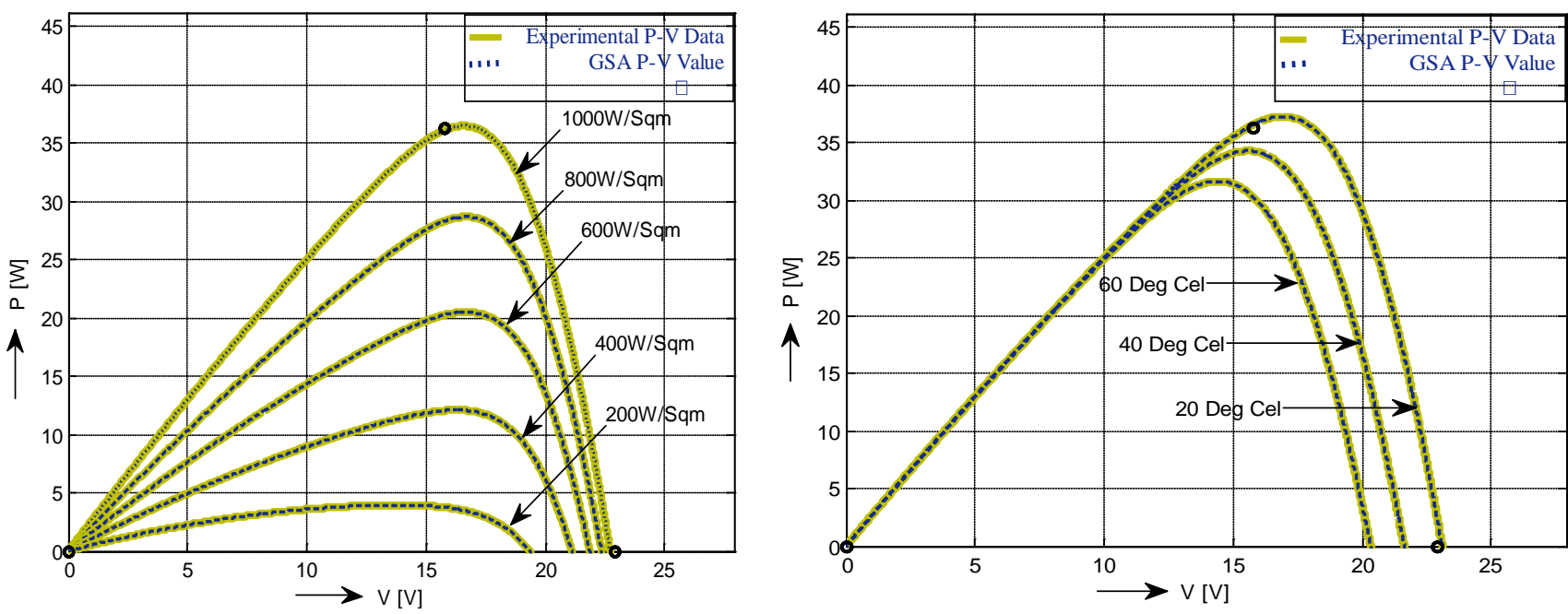

(b)
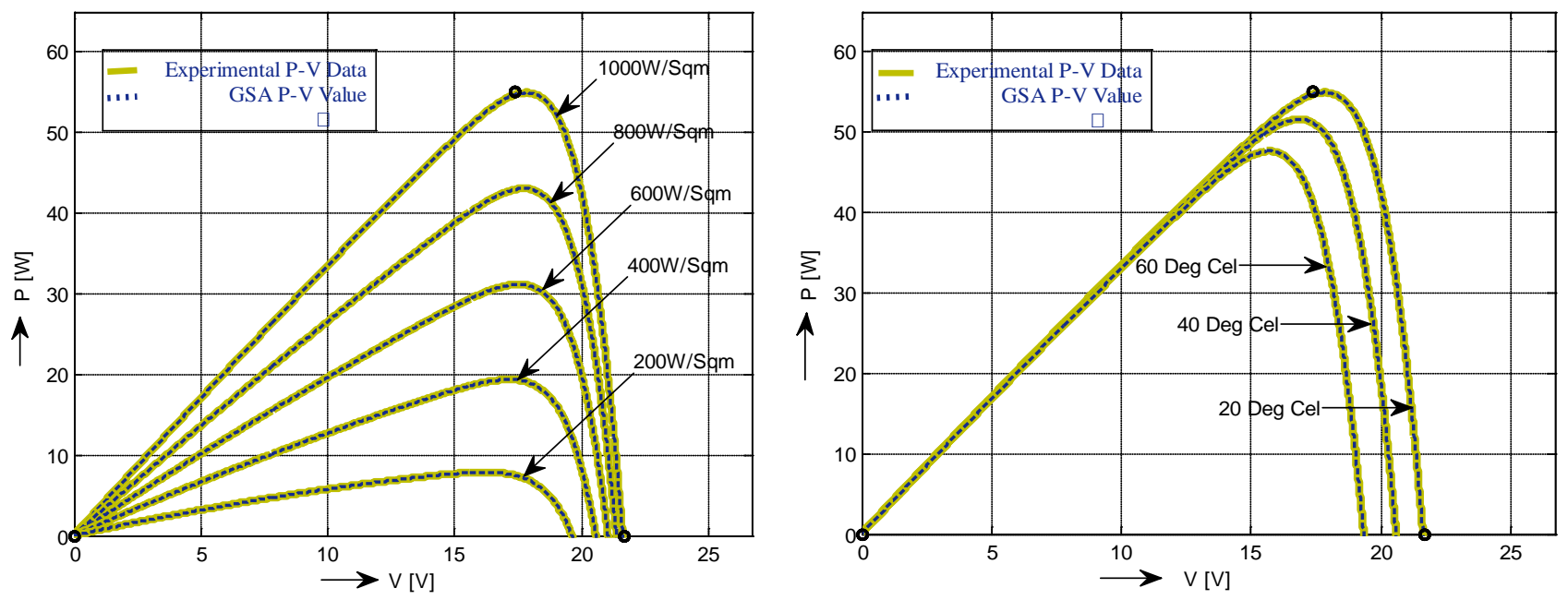

(c)

Figure 5. (a)-(c) P-V curves for different irradiation and temperature levels (a) ST36 (thin film); (b) SM55 (monocrystalline); and (c) ST40 (thin film). 
Table 2. Comparison of computation time using various methods with proposed method GSA for one run.

\begin{tabular}{cccccc}
\hline Parameters & P-DE [7] & B-E [7] & PSO [7] & GA [7] & GSA \\
\hline Time (Sec) & 119 & 119 & 148 & 601 & 32 \\
\hline
\end{tabular}

Table 3. Results for extraction of parameter by GSA for various types of modules (best result for 100 runs).

\begin{tabular}{ccccccc}
\hline \multirow{2}{*}{ Parameters/module } & \multicolumn{2}{c}{ SM55 } & \multicolumn{2}{c}{ ST36 } & \multicolumn{2}{c}{ ST40 } \\
\cline { 2 - 7 } & GSA & P-DE [7] & GSA & P-DE [7] & GSA & P-DE [7] \\
\hline$I_{p v}$ & $3.45 \mathrm{~A}$ & $3.45 \mathrm{~A}$ & $2.689 \mathrm{~A}$ & $2.71 \mathrm{~A}$ & $2.6 \mathrm{~A}$ & $2.68 \mathrm{~A}$ \\
$a$ & 1.1182 & 0.86 & 1.2171 & 2 & 1.1136 & 1.06 \\
$R_{s e}$ & $0.2458 \Omega$ & $0.56 \Omega$ & $0.4109 \Omega$ & $1.46 \Omega$ & $0.4610 \Omega$ & $1.42 \Omega$ \\
$R_{s h}$ & $86.1164 \Omega$ & $4.9 \mathrm{~K} \Omega$ & $110.4652 \Omega$ & $182.6 \Omega$ & $95.3439 \Omega$ & $440.6 \Omega$ \\
Fitness function $J$ & $5.847 \times 10^{-12}$ & $2.4 \times 10^{-2}$ & $9.6421 \times 10^{-12}$ & $2.6 \times 10^{-2}$ & $5.1656 \times 10^{-12}$ & $2.5 \times 10^{-2}$ \\
\hline
\end{tabular}

compared to DE and $R_{s}$-model. Further, the computational time is comparatively low using the proposed method which allows the possibility of real time application of the algorithm towards various modules under different environmental conditions.

\section{References}

[1] Walker, G. (2001) Evaluating MPPT Converter Topologies Using a MATLAB PV Model. Journal of Electrical and Electronics Engineering, Australia Volume, 21, 1-8.

[2] Villalva, M.G. and Gazoli, J.R. (2009) Comprehensive Approach to Modeling and Simulation of Photovoltaic Arrays. IEEE Transactions on Power Electronics, 24, 1198-1208. http://dx.doi.org/10.1109/TPEL.2009.2013862

[3] Belini, A., Bifaretti, S., Lacovone, V. and Cornaro, C. (2009) Simplified Model of a Photovoltaic Module. IEEE Explore on Applied Electronics, 9-10 September 2009, 47-51.

[4] Koutroulis, E., Kolokotsa, D., Potirakis, A. and Kalaitzakis, K. (2006) Methodology for Optimal Sizing of Stand-Alone Photovoltaic/Wind-Generator Systems Using Genetic Algorithms. Solar Energy, 80, 1072-1088. http://dx.doi.org/10.1016/j.solener.2005.11.002

[5] Tina, G.M., Tang, W.H. and Mahdi, A.J. (2011) Thermal Parameter Identification of Photovoltaic Module Using Genetic Algorithm. IET Conference on Renewable Power Generation (RPG 2011), 6-8 September 2011, 1-6. http://dx.doi.org/10.1049/cp.2011.0106

[6] Maherchandani, J.K., Agarwal, C. and Sahi, M. (2012) Estimation of Solar Cell Model Parameter by Hybrid Genetic Algorithm Using MATLAB. International Journal of Advanced Research in Computer Engineering \& Technology, 1, 2278-1323.

[7] Ishaque, K., Salam, Z. and Taheri, H. (2011) Accurate MATLAB Simulink PV System Simulator Based on a Two-Diode Model. JPE Journal of Power Electronics, 11, 2-9.

[8] Salmi, T., Bouzguenda, M., Gastli, A. and Masmoudi, A. (2012) MATLAB/Simulink Based Modelling of Solar Photovoltaic Cell. International Journal of Renewable Energy Research, 2.

[9] Ishaque, K., Salam, Z., Taheri, H. and Shamsudin, A. (2011) A Critical Evaluation of EA Computational Methods for Photovoltaic Cell Parameter Extraction Based on Two Diode 
Model. Solar Energy, 85, 1768-1779. http://dx.doi.org/10.1016/j.solener.2011.04.015

[10] Ishaque, K. and Salam, Z. (2011) An Improved Modelling Method to Determine the Model Parameters of Photovoltaic (PV) Modules Using Differential Evolution (DE). Solar Energy, 85, 2349-2359. http://dx.doi.org/10.1016/j.solener.2011.06.025

[11] Ye, M.Y., Wang, X.D. and Xu, Y.S. (2009) Parameter Extraction of Solar Cells Using Particle Swarm Optimisation. Journal of Applied Physics, 105, 094502. http://dx.doi.org/10.1063/1.3122082

[12] Rashedi, E., Nezamabadi-Pour, H. and Saryazdi, S. (2009) GSA: A Gravitational Search Algorithm. InfSci, 179, 2232-2248. http://dx.doi.org/10.1016/j.ins.2009.03.004

[13] Li, C.S. and Zhou, J.Z. (2011) Parameters Identification of Hydraulic Turbine Governing System Using Improved Gravitational Search Algorithm. Energy Convers Manage, 52, 374381. http://dx.doi.org/10.1016/j.enconman.2010.07.012

[14] Mondal, S., Bhattacharya, A. and Dey, S.H. (2013) Multi-Objective Economic Emission Load Dispatch Solution Using Gravitational Search Algorithm and Considering Wind Power Penetration. Electrical Power and Energy Systems, 44, 282-292. http://dx.doi.org/10.1016/j.ijepes.2012.06.049

[15] Shell Solar Product Information Sheet. http://www.solarcellsales.com/techinfo/technical_docs.cfm

Submit or recommend next manuscript to SCIRP and we will provide best service for you:

Accepting pre-submission inquiries through Email, Facebook, LinkedIn, Twitter, etc. A wide selection of journals (inclusive of 9 subjects, more than 200 journals)

Providing 24-hour high-quality service

User-friendly online submission system

Fair and swift peer-review system

Efficient typesetting and proofreading procedure

Display of the result of downloads and visits, as well as the number of cited articles Maximum dissemination of your research work

Submit your manuscript at: http://papersubmission.scirp.org/

Or contact cs@scirp.org 